\title{
Educomunicación y noticias científicas en los libros de Ciencias para el Mundo Contemporáneo
}

\section{Educommunication and Scientific News in Science for contemporary world's textbooks}

\section{Lorenzo Hernández-Villalobos Ma Rut Jiménez Liso}

Universidad de Almería

\begin{abstract}
Resumen: La asignatura Ciencias para el Mundo Contemporáneo contiene finalidades y objetivos ligados al desarrollo de las alfabetizaciones científica y mediática de todos los estudiantes de Bachillerato. En esta materia obligatoria el desarrollo de la competencia científica se plantea desde los conocimientos y habilidades científicos necesarios para comprender, participar y tomar decisiones sobre las controversias sociocientíficas en los medios de comunicación (Educomunicación). En este artículo mostramos un análisis de la presencia, del contenido y del tratamiento de las noticias científicas incluidas en los libros de texto de esta asignatura. Los resultados ponen de manifiesto que sólo cinco editoriales incluyen noticias científicas actuales en sus libros de texto, situándolas en posiciones secundarias y anecdóticas (anexos). El análisis de contenido muestra que el criterio de selección de las noticias científicas se realiza en función de los bloques temáticos y no de la mayor presencia en los medios de comunicación (prensa), así como la mayoría de las noticias son eventos de investigación en vez de catástrofes o eventos políticos, mayoritarios en la prensa. La principal fuente de divulgación científica, es decir, las redes sociales (Twitter, Facebook), están ausentes en los libros de texto. Esto puede generar lejanía con el público receptor, los estudiantes de Bachillerato. Estos análisis contribuyen a reflexionar sobre la oportunidad perdida para la educomunicación de esta asignatura, que tiene sus días contados con la próxima implantación de la LOMCE.
\end{abstract}

Palabras clave: Ciencias para el Mundo Contemporáneo, Educomunicación, Competencia científica, Libros de texto, Noticias científicas.

Abstract: Science for contemporary world is a Spanish High School compulsory subject. It contains goals linked to the development of scientific, media and information literacies for all High School students. On this compulsory subject the development of scientific competence arises from the scientific knowledge and skills necessary to understand, to participate and to make decisions about social scientific controversies in the media (Educommunication). In this paper we show presence and content analysis of scientific news included in the SCW-textbooks. The results of this paper show that only five publishers include current science news on their textbooks, placing them on anecdotal positions (annexes). The content analysis shows that the selection criterion of scientific news is performed according to the thematic blocks and not the greater presence in the media. Most of the news selected is related to researches events instead of disasters or politics events, main news in the newspapers. The main source of scientific divulgation through social networks (Twitter, Facebook) is not included on textbooks. It could generate distance to receptor public (High School students) because they use mainly this networks to communicate among themselves. These analyses help us to think about the missed opportunity for Educommunication of this subject, that has a deadline with the upcoming implementation of the LOMCE.

Keywords: Science for Contemporary World, Educommunication, Scientific Competence, Textbooks, Scientific News.

(Fecha de recepción: agosto, 2015, y de aceptación: abril, 2016)

DOI: 10.7203/DCES.31.6841 


\section{Introducción}

La asignatura de Ciencias para el Mundo Contemporáneo (en adelante CMC), obligatoria para el primer curso de Bachillerato con el desarrollo de la LOE en 2007 (MEC, 2007), tiene sus días contados cuando se implemente en su totalidad la LOMCE ${ }^{1}$. Esto nos resulta sorprendente por cuanto era una asignatura demandada ampliamente desde la investigación en didáctica de las ciencias para salvar la necesidad de tiempo, libertad y recursos para alfabetizar científicamente a los estudiantes de Bachillerato (Pedrinaci, 2008) que nos igualaba a otras materias similares de otros países europeos, por ejemplo, Science for public Understanding en Reino Unido, Enseignement scientifique, série littéraire en Francia (Fernández-González, 2008), Algemene Natuurwetenschappen en Holanda.

CMC ha pasado sin pena ni gloria por el sistema educativo estatal desde sus inicios. Eclipsada por la controversia generada por Educación para la ciudadanía fue implementada sin debate público sobre sus contenidos (algunos polémicos como las células madre) y ante esa tibieza, su derogación tampoco ha provocado ríos de tinta de defensores o detractores.

La equivalente asignatura en el marco legislativo actual (LOMCE) no parece recibir mejor tratamiento si atendemos a la posición que ocupa en las matrículas (fig. I) y las asignaturas acompañantes entre las que el alumnado debe elegir una (todas evaluables).

\section{Figura I. Ejemplo de matrícula de optativas del alumnado de $1^{\circ}$ Bachillerato LOMCE (curso 15-16)}

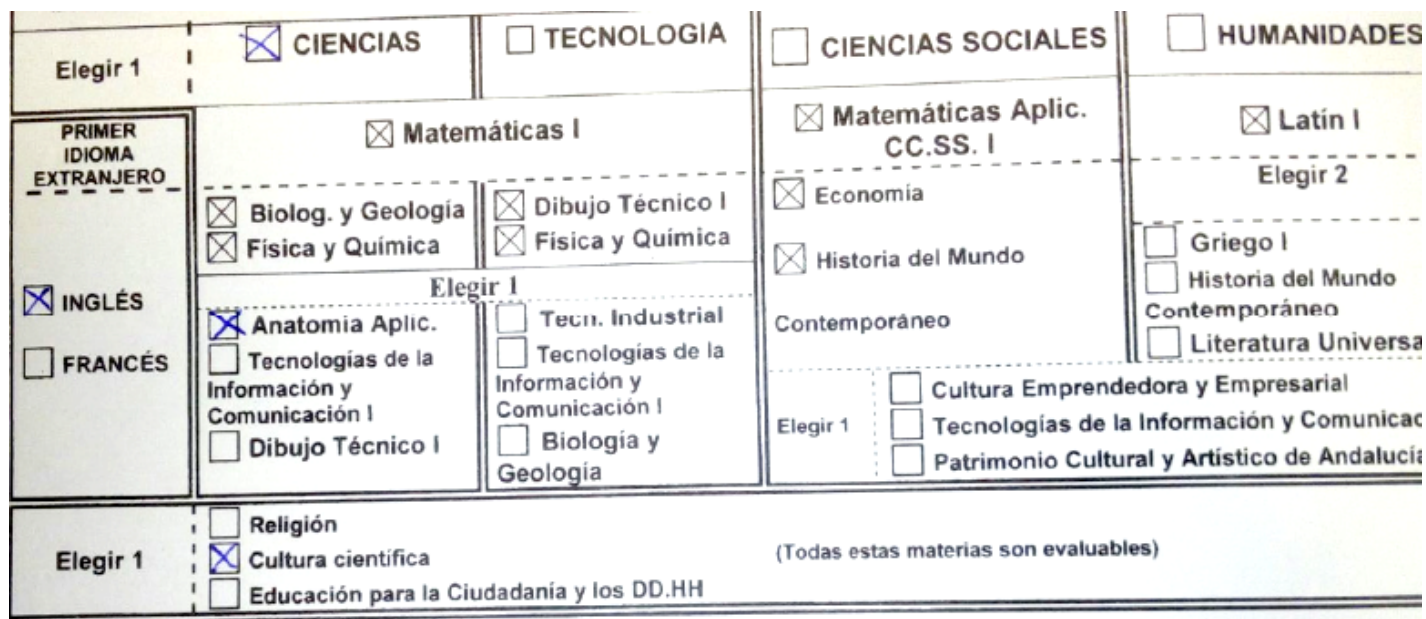

${ }^{1}$ La Ley Orgánica 8/2013, de 9 de diciembre, para la mejora de la calidad educativa BOE 10 de diciembre de 2013 disponible en https://www.boe.es/diario_boe/txt.php?id=BOE-A-2013-12886. 
Esta indiferencia, y su posterior opcionalidad, podría provenir de las fricciones generadas por la asignatura entre sus participantes. Por un lado con los estudiantes debido a su obligatoriedad para todos, todos los de $1^{\circ}$ de Bachillerato (17 años) ya fueran de ciencias o de letras: en el caso de los estudiantes que optaron por ciencias por la incomprensión de tener que repetir contenidos muy similares a los de la ESO, en el caso de los estudiantes de letras por tener que estudiar contenidos ya rechazados y abandonados. Por otro lado, fricciones similares manifiesta el profesorado, provenientes del insuficiente conocimiento de contenidos tan dispares de la asignatura (de biología, geología, física y química) y de la inseguridad que generan actividades poco habituales en las clases de ciencias como los debates que les suscitan preguntas del tipo ¿cómo evaluamos los debates? (Pipitone, 2013).

Los debates parecen ser el eje central de esta asignatura pues entre sus finalidades se encuentran las controversias sociocientíficas, aspectos íntimamente ligados a la alfabetización mediática y de la información (en adelante $\mathrm{MIL}^{2}$ ) para su contribución a la alfabetización científica de los estudiantes:

Los medios de comunicación presentan de forma casi inmediata los debates científicos y tecnológicos sobre temas actuales. Cuestiones como la ingeniería genética, los nuevos materiales, las fuentes de energía, el cambio climático, los recursos naturales, las tecnologías de la información, la comunicación y el ocio o la salud son objeto de numerosos artículos e, incluso, de secciones especiales en la prensa. Los ciudadanos del siglo XXI, integrantes de la denominada «sociedad del conocimiento», tienen el derecho y el deber de poseer una formación científica que les permita actuar como ciudadanos autónomos, críticos y responsables. Para ello es necesario poner al alcance de todos los ciudadanos esa cultura científica imprescindible y buscar elementos comunes en el saber que todos deberíamos compartir (MEC, 2007).

Al leer este fragmento del Real Decreto de introducción de las enseñanzas mínimas para CMC, se pone de manifiesto la estrecha relación entre ambas alfabetizaciones (científica y mediática) dado su carácter eminentemente proactivo con la comprensión de los temas científicos actuales y de ciencia en construcción. Por tanto, si la asignatura CMC quisiera ser fiel a sus principios y finalidades o contribuir al desarrollo de las alfabetizaciones científica y mediática, necesita que los temas de actualidad y las noticias que generan controversia sean su eje vertebrador.

En el presente artículo queremos averiguar si esto es así y, para ello,

\footnotetext{
${ }^{2}$ MIL siglas en inglés de media and information literacy.
} 
nos aproximamos a la realidad de las aulas de CMC a través de los libros de texto diseñados para ella y del análisis de presencia y contenido de las noticias científicas que contengan. De esta forma analizaremos si contribuyen a la educomunicación o amplían la decepción del profesorado que quiera utilizar en sus aulas las controversias sociocientíficas aparecidas en prensa para el desarrollo de la competencia científica de ciudadanos capaces de tomar decisiones sobre ciencia.

\section{CMC: Una oportunidad de desarrollar la educomunicación científica}

La competencia científica es definida como la capacidad de emplear el conocimiento científico para identificar preguntas y extraer conclusiones basadas en hechos, con el fin de comprender y poder tomar decisiones sobre el mundo natural y sobre los cambios que ha producido en él la actividad humana (OCDE, 2006). La toma de decisiones sobre los cambios de la actividad humana obliga a que la educación científica se centre en plantear las controversias sociocientíficas actuales y, desde ahí, repensar el conocimiento científico necesario para comprender las diferentes conclusiones (Doménech y Márquez-Bargalló, 2014). Desde este punto de vista, la competencia científica está inexorablemente unida a la educomunicación pues, los medios de comunicación generan o se hacen eco de las controversias sociocientíficas. Coincidimos con uno de los expertos participantes en un estudio Delphi que, al señalar los contenidos necesarios para participar en las diferentes áreas de la vida, indica: estamos inmersos en el mundo de internet, periódicos, televisión y otros massmedia. Ser críticos con la información es esencial para la toma de decisiones y capacita a los ciudadanos a jugar un papel activo en la construcción de una sociedad más libre y democrática (Blanco, España, González y Franco, 2015). En recomendaciones del National Research Council (2012), al final de la educación obligatoria, los estudiantes deberían tener suficiente conocimiento de prácticas, ideas centrales de la ciencia como para intervenir críticamente en las discusiones públicas sobre temas científicos.

Las noticias científicas y ambientales comparten objetivos similares (educar, entretener y enganchar ${ }^{3}$ ) con la educación científica aunque con prioridades, destinatarios, contextos, epistemologías y conocimientos diferentes (Baram-Tsabari y Osborne, 2015), de manera que no debería producir ninguna fricción su uso en las clases de CMC para lograr las finalidades para las que fue pensada. La introducción de noticias científicas en las aulas de CMC requiere evaluar críticamente los tex-

3 Hemos traducido así el término inglés engange aunque los tres objetivos de la información tradicionalmente se tradujeron como formar, informar y entretener (educate, entertain and engage). 
tos mediáticos y fuentes de información, para ser capaz de producirlos, de analizarlos desde el debate democrático y la participación social, en definitiva de desarrollar la MIL con estudiantes de secundaria, como demanda el curriculum MIL de la UNESCO (Wilson, 2012), pues como señalan Gonzálvez-Pérez y Contreras-Pulido (2014) ser ciudadano hoy, es ser ciudadano en lo mediático.

Para que la educomunicación contribuya al desarrollo de la competencia científica ligada a la toma de decisiones ante las controversias sociocientíficas con las que nos topamos cada día, es necesario que tenga presencia clara en la educación formal. En el presente artículo nos vamos a centrar en la presencia que tiene en la asignatura de CMC, en concreto, nos centraremos en el análisis de la presencia y el contenido de las noticias de prensa escrita que aparezcan en los libros de texto de CMC.

Para justificar por qué nos centramos en el análisis de los libros de texto, es necesario reconocer la indiscutible importancia que los profesores y los estudiantes conceden a los libros de texto en las clases de Ciencias. Como muestran algunos estudios ya clásicos (Chiappeta, Sethna y Fillman, 1991): casi todos los profesores utilizan un solo libro de texto la mayor parte del tiempo en clase, incluso en CMC donde, al ser una materia nueva, el libro de texto sigue siendo la única herramienta de selección de contenidos y actividades (Pipitone, 2013) o en educomunicación donde también se detecta que los docentes utilizan un solo libro de texto como única fuente y concreción del currículo MIL (Sur, Ünal y Iseri, 2014), de aquí que el libro de texto se convierta en objeto de estudio por parte de la investigación.

\section{Objetivos y metodología}

De la multitud de aspectos que pueden ser estudiados en los libros de texto como la estructura sustantiva, la argumentación o la comprensión que generan, en este artículo nos situamos más próximos a quienes cuantifican los aspectos formales (número de capítulos, ilustraciones, actividades trabajos prácticos, etc.) y los relaciona con las referencias a la realidad (Rivera e Izquierdo, 1997).

Para que los libros de CMC contribuyan a favorecer la educomunicación deberían, en primer lugar, contener noticias científicas o reseñas y, en segundo lugar, que su contenido ofrezca al profesorado posibilidades de utilizarlas en el aula de ciencia para el desarrollo de la competencia científica. Si este estudio pusiera de manifiesto la ausencia de noticias o el tratamiento inadecuado podríamos extraer conclusiones en relación a que la insatisfacción del profesorado con la asignatura también puede provenir de la decepción que estos materiales le hayan producido.

Por tanto, los dos objetivos fundamentales del presente estudio son, por un lado, analizar si las editoriales han tenido una intención manifiesta de introducir noticias en los libros de CMC editados en el primer año de implanta- 
ción de la LOE y, para ello, contabilizaremos las noticias o reseñas en todas las páginas de los libros y los compararemos (para su calibración) con los de Física y Química (en adelante FyQ) de idéntico nivel educativo ( $1^{\circ}$ de Bachillerato). Para ello, utilizaremos una metodología de análisis documental similar al utilizado en estudios anteriores de análisis de presencia y contenido de las noticias científicas (Jiménez-Liso, HernándezVillalobos y Lapetina, 2010, adaptación de Dimopoulos y Koulaidis, 2002).

Para analizar el contenido de las noticias que aparezcan en los libros de CMC, analizaremos:

- La fecha de la publicación con el objeto de caracterizar la actualidad (fechas próximas a la fecha de edición del libro) o no.

- La fuente de la que proviene para relacionarla con la proximidad al público receptor si las fuentes utilizadas son las redes sociales tan utilizadas por los estudiantes o mantienen las fuentes tradicionales como la prensa nacional o internacional de amplia tirada.

- La importancia que el libro concede a las noticias o reseñas presentes en función de su posición en el capítulo. De manera que consideraremos como posición privilegiada las noticias que aparezcan en el seno del tema o como aplicación final frente a las que aparezcan como anecdóticas en los anexos o márgenes o las que muestran una imagen de pretexto o contextualización inicial cuando aparezcan exclusivamente al principio de la noticia. Los resultados de esta sección nos permitirá relacionar los libros de texto con el perfil de profesorado que los consume en función de los resultados de Pipitone (2013).

- La temática de las noticias científicas, las describiremos en Áreas de la vida en las noticias de prensa de los libros de CMC (apartado 6.2) para analizar si la selección de noticias está influida mayoritariamente por el currículo (DíazMoreno y Jiménez-Liso, 2012) o por las noticias habituales en la prensa (controversias noticiables, Jarman y McClune, 2007).

- Por último, haremos una clasificación de las noticias por tipo de evento con el objetivo de explorar si la selección de las noticias en los libros de CMC focaliza la atención en catástrofes o eventos negativos o, por el contrario, se centran en destacar los avances tecnológicos o los eventos políticos que den una imagen de la ciencia en construcción y sometida a intereses socioeconómicos, en definitiva más humana.

Los resultados han sido obtenidos tras una categorización de manera independiente por ambos investigadores, de manera que cada noticia estuviera en una sola categoría. La coincidencia entre ambos investigadores ha sido de más del $90 \%$ para los apartados 6.2 y 6.3 y del $100 \%$ en el resto. 
Los resultados del análisis de presencia y contenido de las noticias científicas que vamos a desarrollar en el presente artículo pretende ser un instrumento para que el profesorado de CMC utilice las noticias en los libros planteando diferentes puntos de vista político (Oliveras y Sanmartí, 2009) o como controversias sociocientíficas (Pipitone, 2013) utilizando también la presencia de eventos negativos y catástrofes para problematizar y contextualizar la asignatura.

\section{Presencia (o ausencia) de prensa en los libros de CMC}

En este apartado queremos analizar si los libros de CMC ofrecen artículos o reseñas de noticias científicas controvertidas o relacionadas con avances recientes de manera que el profesorado interesado en educomunicar en CMC no tenga que seleccionarlas por otros cauces (blogs, redes sociales, etc.). Para ello hemos contabilizado las noticias y reseñas que aparecen en once libros de CMC de $1^{\circ}$ de Bachillerato de 2008 (primer año de implantación de la asignatura) de las principales editoriales a disposición del profesorado Mc Graw Hill, Editex, Vicens Vives, Everest, Santillana Pearson, Alhambra, Bruño, Oxford, SM, Edelvives y Algaida (Anaya), de las cuales sólo cinco editoriales ofrecen artículos de prensa y reseñas (tabla I).

Estos resultados así aislados sólo servirían para comparar entre editoriales y concluir si una editorial aporta más noticias que otras. Sin embargo, para saber si en los libros de CMC ha habido una intención clara de introducir noticias, con el objeto de poder calibrar si la presencia de noticias científicas en los libros de texto de CMC es elevada o no, hemos contabilizado las noticias que aparecen en seis libros de Física y Química del mismo curso ( $1^{\circ}$ Bachillerato) del año 2008 y siete del año 2015 de las mismas editoriales de aquellos libros de CMC donde hemos encontrado utilización de noticias científicas (Anaya, SM, Mc Graw Hill, Editex y Edelvives). De estas cinco editoriales, solo una, la editorial SM (año 2008), incorpora 35 reseñas de noticias, casi la mitad de noticias que ofrece para el libro de CMC del mismo curso (68 noticias-reseñas en CMC). Sin embargo, en la edición de 2015 no aparece ninguna reseña. Por tanto, estas editoriales sí han contemplado la necesidad de incorporar (o aumentar) las noticias de prensa en sus libros de CMC mientras que para aprender FyQ no lo han visto necesario. De las editoriales que no incluyen noticias en los libros de CMC no podemos extraer conclusiones pues la decisión editorial puede provenir por evitar la caducidad de los libros al perder actualidad las noticias que insertaran. Este argumento se corroboraría o rechazaría si todas las noticias que aparezcan en los demás libros (que sí las incluyen) fuera muy próximas a la fecha de publicación y esto es así pues en torno al $75 \%$ de las noticias son muy próximas a la fecha de publicación de los libros (2008, primer año de implantación de la asignatura $\mathrm{CMC}$ ), por lo que parece que la 
ausencia de noticias pueda estar fundamentada en evitar que el libro se quede obsoleto con la presencia de noticias que ya no sean actuales.

La búsqueda de noticias-reseñas, por otro lado, nos ha permitido seleccionar 162 artículos o reseñas de libros de CMC y 35 de un libro de FyQ (editorial $\mathrm{SM})$ que nos servirán de muestra para el análisis del contenido de las noticias científicas en los citados libros.

\section{Importancia de la prensa en los libros de CMC}

La importancia de una noticia científica en la prensa escrita se suele detectar por la conjunción de varios indicadores: el tamaño, las imágenes, si se encuentra en la portada, si el grueso de la noticia se encuentra en hoja impar o par, etc. (Dimopoulos y Koulaidis, 2002). En el presente estudio, las noticias están recortadas de sus periódicos con lo que debemos indagar la importancia desde otra perspectiva: la situación de las noticias en el libro de texto. Por ello, hemos contabilizado cuántas de las 162 noticias encontradas en los libros de CMC (y las 35 de FyQ, tabla I) se encuentran en las páginas iniciales, entre las actividades intermedias o finales (de síntesis) del tema o en los Anexos. De manera que, como utilizaban Jiménez-Liso, Sánchez-Guadix y De Manuel (2002), hemos contabilizado las noticias y reseñas que aparecían en cada sección del tema.

En el estudio de Jiménez-Liso, Sánchez-Guadix y De Manuel (2002) sobre Química cotidiana en las actividades de los libros de texto, destacaban que estas

Tabla I. Localización de las noticias en los libro de texto de CMC y FyQ

\begin{tabular}{|c|c|c|c|c|c|}
\hline $\begin{array}{c}\text { Libro de } \\
\text { Texto }\end{array}$ & $\begin{array}{c}\text { Páginas } \\
\text { iniciales }\end{array}$ & $\begin{array}{c}\text { Actividades } \\
\text { intermedias }\end{array}$ & $\begin{array}{c}\text { Actividades } \\
\text { finales }\end{array}$ & Anexos & Total \\
\hline Mc Graw-Hill & 0 & 0 & 0 & $30(100 \%)$ & $\mathbf{3 0}$ \\
\hline Editex & 0 & 0 & $56(100 \%)$ & 0 & $\mathbf{5 6}$ \\
\hline Edelvives & 0 & $\begin{array}{c}4+1(\text { columna } \\
\text { margen }) \\
(18,5 \%)\end{array}$ & $5(18,5 \%)$ & $17(62,9 \%)$ & $\mathbf{2 7}$ \\
\hline Algaida & 0 & & $1(12,5 \%)$ & $7(87,8 \%)$ & $\mathbf{8}$ \\
\hline SM & $26(63,4 \%)$ & $\begin{array}{c}7+1(\text { columna } \\
\text { margen }) \\
(19,5 \%)\end{array}$ & $1(2,4 \%)$ & $6(14.6 \%)$ & $\mathbf{4 1}$ \\
\hline Total & $\mathbf{2 6 ~ ( 1 6 \% )}$ & $\mathbf{1 3 ( 8 \% )}$ & $\mathbf{6 3} \mathbf{( 3 9 \% )}$ & $\mathbf{6 0 ~ ( 3 7 \% )}$ & $\mathbf{1 6 2}$ \\
\hline SM FyQ & $\mathbf{0}$ & $\mathbf{0}$ & $\mathbf{0}$ & $\mathbf{3 5}(\mathbf{1 0 0 \% )}$ & \\
\hline
\end{tabular}


disminuían del comienzo del tema al final lo que ponía de manifiesto que los libros reducían la contextualización al comienzo del tema y desaparecía de las aplicaciones de la teoría (final del tema).

En nuestro estudio sobre la prensa en los libros de CMC (tabla I) podemos ver que la mayoría de las editoriales que incluyen noticias las reservan para los anexos: todas las de McGraw-Hill, casi todas las de Algaida $(87,8 \%)$ o la mayoría de Edelvives $(62,9 \%)$. Al sacarla del cuerpo del tema e incluirlas en los anexos indica la escasa importancia que se le está concediendo al uso de las noticias-reseñas de prensa en los citados libros.

La editorial SM utiliza mayoritariamente las posiciones iniciales $(63,4 \%$ de sus noticias-reseñas) y prácticamente desaparecen de las actividades finales o las reservan para los anexos $(14,6 \%)$ lo que parece indicar un perfil del uso de noticias claramente de introducción-motivación inicial alejado de la aplicación o de la toma de decisiones fundamentadas en la teoría que hayan expuesto en las páginas del tema.

Editex, por el contrario, además de ser el libro que tiene mayor frecuencia de noticias-reseñas (56) las reserva en su totalidad para formar parte de las actividades finales (de aplicación y síntesis) con lo que su importancia parece ser reconocida y muestra un perfil del uso de noticias claramente de aplicación.

Estos resultados pueden estar relacionados con el perfil de profesorado que consume los libros. En este sentido,
Pipitone (2013) detecta cuatro perfiles de docentes de CMC: perfil epistémico (centrado en los modelos de la ciencia), perfil utilitario (centrado en los contextos), perfil controvertido (debate sobre controversias socio-científicas) y el perfil académico-disciplinar. Cada profesor-a seleccionará el libro de texto que más se adecue a su perfil para lograr una coherencia con su visión del proceso de enseñanza-aprendizaje (JiménezValladares y Perales, 2001). En este sentido, a modo de ejemplo, un profesor cuyo enfoque pueda englobarse como perfil utilitario estará más próximo a seleccionar el libro de CMC de la editorial SM que las utiliza al comienzo de la unidad a modo de pretexto que el de la editorial Editex (noticias en las actividades finales) que será seleccionado por docentes con perfil epistémico, más centrado en la aplicación de modelos científicos.

\section{Análisis del contenido de la prensa en los libros de CMC}

El análisis del contenido continúa con la detección de las fuentes de las que proceden las noticias-reseñas utilizadas en los libros de CMC, las áreas de la vida más utilizadas.

Fuentes de información de la que proceden las noticias científicas en los libros de CMC

Los libros suelen extraer sus noticiasreseñas de la prensa de mayor tirada: El País (42,1\%), El Mundo (27,6\%) que 
son los periódicos con mayor presencia de noticias científicas seguidas del ABC $(11,9 \%)$. La categoría otras $(16,3 \%, 24$ noticias) requiere un análisis más fino con idea de valorar si corresponden a redes sociales (twitter, facebook) o blogs más próximos a las fuentes de información de los estudiantes de Bachillerato o, por el contrario, son los tradicionales pero de menor tirada que los anteriores. En la tabla II podemos observar que casi la mitad de estas fuentes diferen- tes corresponden a medios científicodivulgativos como la revista Investigación y ciencia pero el resto son prensa no especializada de ámbito local (Diario Sur) o extranjero (BBC mundo) o en formato agencias (EFE).

Estos datos ponen de manifiesto la todavía dependencia de los libros de texto a las fuentes tradicionales de divulgación científica, tal vez, por la necesidad de avalar con fuentes reconocidas el prestigio de las noticias cien-

Tabla II. Frecuencia de noticias en los libros de CMC en otras fuentes

\begin{tabular}{|l|l|}
\hline Clasificación (frecuencia) & Otras fuentes (frecuencia) \\
\hline \multirow{4}{*}{$\begin{array}{l}\text { Medios científico- } \\
\text { divulgativos (10) }\end{array}$} & Cnvestigación y ciencia (4) \\
& Ciencia (1) \\
& National Geographic (1) \\
& Boletín de prensa de la Real Sociedad de Ciencias \\
& de Suecia (1) \\
& Diario Verde (1) \\
& Innova Almirall (1) (Empresa farmacéutica) \\
\hline \multirow{5}{*}{ Medios locales (5) } & La opinión de Málaga (1) \\
& S.R. Murcia-Zaragoza(1) \\
& Periódico de Aragón (1); \\
& Diario Sur (1) \\
& Panorama Actual (1) \\
\hline \multirow{5}{*}{ Agencias (5) } & Agencia de noticias (2) \\
& Europa press (1) \\
& EFE Londres (1); \\
& EFE Madrid (1) \\
\hline Medios extranjeros (4) & BBC Mundo.com (1) \\
& Publicaffairs.llnl.gov (1) \\
& www.clarin.com (Argentina) (1) \\
& ATB noticias (1) Colombia \\
\hline Otros (1) & El economista (1) \\
\hline & \\
\hline &
\end{tabular}


tíficas que ofertan sin tener en cuenta que la mayoría de la divulgación científica actualmente se está desarrollando a través de redes sociales y blogs de ciencias (Minol et. al., 2007 citado por Segado-Boj et. al., 2014) que las acercaría al público receptor, estudiantes de Bachillerato que utilizan mucho más las redes sociales como medio de información y comunicación que las fuentes tradiciones de información.

Áreas de la vida en las noticias de prensa de los libros de CMC

Las noticias agrupadas por las áreas de la vida a las que influyen nos pueden aportar información acerca del contenido de la noticia que ampliaremos con el agrupamiento de titulares de prensa para describir la conexión con el currículo de CMC. Esta corres- pondencia entre noticia y curriculum se puede hacer directamente indicando en qué temas aparecen o son utilizados en las actividades, pero hemos preferido hacerlo al margen de esta presencia para valorar realmente el contenido en relación a las áreas más utilizadas y poder compararlas con la frecuencia de aparición en los periódicos o con las propuestas que se plantean en la literatura didáctica (Díaz-Moreno y Jiménez-Liso, 2012) que resumimos en la tabla III.

En la tabla III podemos observar que en los libros de CMC mayoritariamente aparecen noticias sobre Medioambiente (29\%) que concuerda con el bloque 4 de CMC Hacia una gestión sostenible del planeta (MEC 2007) seguidas por las noticias sobre Salud $(21,6 \%)$ también relacionado con el bloque 3 Vivir más, vivir mejor y que en las reformulaciones específicas para cada comunidad

Tabla III. Frecuencia de noticias en los libros de CMC en otras fuentes

\begin{tabular}{|c|c|c|c|c|}
\hline \multirow{2}{*}{$\begin{array}{l}\text { Áreas } \\
\text { (Díaz-Moreno y Jiménez } \\
\text { Liso, 2012) }\end{array}$} & \multirow[b]{2}{*}{ CMC } & \multicolumn{2}{|c|}{ Periódicos } & \multirow{2}{*}{$\begin{array}{l}\text { Propuestas } \\
\text { didáctic. }{ }^{* *}\end{array}$} \\
\hline & & $\begin{array}{c}\text { Internacional } \\
\text { Grecia }^{* * *}\end{array}$ & $\begin{array}{c}\text { Local } \\
\text { Almería* }\end{array}$ & \\
\hline Salud & $21,6 \%$ & & $42 \%$ & $12,4 \%$ \\
\hline Biotecnología (genética) & $3,7 \%$ & \multirow{2}{*}{$18,1 \%$} & & $39,8 \%$ \\
\hline Biología (evolución) & $1,9 \%$ & & & $8,3 \%$ \\
\hline Medioambiente & $29 \%$ & $12 \%$ & $10 \%$ & $29,5 \%$ \\
\hline Astronomía & $8 \%$ & $8,2 \%$ & & $1,7 \%$ \\
\hline Nanotecnología & $1,9 \%$ & & & $8,3 \%$ \\
\hline Tecnología & $14,8 \%$ & $31,7 \%$ & & \\
\hline Agrarias & & & $22 \%$ & \\
\hline
\end{tabular}

* Datos extraídos de Lapetina (2005); ** Datos extraídos de Díaz-Moreno y Jiménez-Liso (2012);

*** Datos extraídos de Dimopoulos y Koulaidis (2002) 
se desdobla en dos tanto en Cataluña: Ciencia, salud y estilos de vida//Biotecnología y sociedad como en Andalucía en Células madre ¿Clonación?//Salud y enfermedades de nuestro tiempo (Tárraga y De Pro, 2013).

Aunque podemos encontrar noticias relacionadas con cada uno de los bloques de contenidos de CMC (tabla IV), es evidente que la presión curricular domina la selección de las noticias en los libros quedando en un segundo plano la actualidad o las temáticas noticiables para la prensa (tabla III) como la tecnología y la bio-tecnología (Dimopoulos y Koulaidis, 2002) o las cuestiones agrarias destacadas en la prensa local (Lapetina, 2005). Por tanto, si la temática (y no la actualidad) es el principal criterio de selección de las noticias, no encontramos explicación a que las noticias no tengan mayor presencia en los libros de CMC (apartado 3 del artículo).

\section{Tabla IV. Ejemplos de titulares de las noticias agrupadas por áreas temáticas}

\begin{tabular}{|c|c|c|c|}
\hline Título del artículo & $\begin{array}{l}\text { Fecha } \\
\text { Fuente }\end{array}$ & Área & Editorial \\
\hline $\begin{array}{l}\text { Con los biocombustibles no se ahorran } \\
\text { emisiones de } \mathrm{CO}_{2} \text {. }\end{array}$ & $\begin{array}{l}\text { 12-12-2007 } \\
\text { El País }\end{array}$ & \multirow{3}{*}{ Medioambiente } & Edelvives \\
\hline $\begin{array}{l}\text { La CEOE cree que la energía nuclear es la más } \\
\text { ecológica }\end{array}$ & $\begin{array}{l}\text { 12-12-2007 } \\
\text { El País }\end{array}$ & & $\mathrm{SM}$ \\
\hline Ecotasa para automóviles en Milán & $\begin{array}{l}4-1-2008 \\
\text { ABC }\end{array}$ & & Anaya (Algaida) \\
\hline $\begin{array}{l}\text { Nigeria demanda a Pfizer por ensayar en niños } \\
\text { un fármaco sin permiso }\end{array}$ & $\begin{array}{l}\text { 6-6- } 2007 \\
\mathrm{ABC}\end{array}$ & \multirow{3}{*}{ Salud } & Editex \\
\hline $\begin{array}{l}\text { Un hospital de Sevilla cura a un feto de espina } \\
\text { bífida en al } 27^{\mathrm{a}} \text { semana de embarazo }\end{array}$ & $\begin{array}{l}7-9-2007 \\
\text { El País }\end{array}$ & & Anaya (Algaida) \\
\hline $\begin{array}{l}\text { Describen paso a paso cómo se blinda una } \\
\text { bacteria frente a los antibióticos }\end{array}$ & $\begin{array}{l}22-5-2007 \\
\mathrm{ABC}\end{array}$ & & Mc Graw-Hill \\
\hline $\begin{array}{l}\text { Dos españolas descubren cómo se recupera una } \\
\text { estrella tras explotar. }\end{array}$ & $\begin{array}{l}11-10-2002 \\
\text { El Mundo }\end{array}$ & \multirow{2}{*}{ Astronomía } & Mc Graw-Hill \\
\hline $\begin{array}{l}\text { Dudas y críticas en EEUU sobre la utilidad } \\
\text { científica de la Estación Espacial Internacional. }\end{array}$ & $\begin{array}{l}\text { 7-12-2006 } \\
\text { El País }\end{array}$ & & Edelvives \\
\hline $\begin{array}{l}\text { Un nuevo sistema GPS indica cuándo es mejor } \\
\text { el transporte público que el coche }\end{array}$ & $\begin{array}{l}31-1-2008 \\
\text { El Mundo }\end{array}$ & \multirow{2}{*}{ Tecnología } & $\mathrm{SM}$ \\
\hline $\begin{array}{l}\text { La edad, principal traba para la utilización de } \\
\text { Internet y el móvil. }\end{array}$ & $\begin{array}{c}6-6-2007 \\
\mathrm{ABC}\end{array}$ & & Mc Graw-Hill \\
\hline $\begin{array}{l}\text { Alerta científica sobre los riesgos para la salud } \\
\text { y el medioambiente de la nanotecnología. }\end{array}$ & $\begin{array}{l}8-8-2004 \\
\text { ABC }\end{array}$ & $\begin{array}{l}\text { Nuevos } \\
\text { materiales }\end{array}$ & Mc Graw-Hill \\
\hline
\end{tabular}


Clasificación de las noticias en los

libros de CMC por tipo de evento

La clasificación de las noticias según el tipo de evento utilizada por Dimopoulos y Koulaidis (2002) nos aportará información sobre si los libros de CMC quieren destacar las catástrofes y eventos negativos relacionados con la problemática ambiental (Vilchez, 2009) o, por el contrario, se centran en destacar los avances tecnológicos o los eventos políticos que den una imagen de la ciencia en construcción y sometida a intereses socioeconómicos, en definitiva más humana.

En la tabla V mostramos la frecuencia de noticias agrupadas según cada tipo de evento y un ejemplo representativo de dicho evento seleccionados entre los presentes en los libros de texto de CMC.

\section{Tabla V. Ejemplos representativos de noticias-reseñas de los libros de CMC agrupadas por tipo de evento}

\begin{tabular}{|c|c|c|}
\hline Tipo evento & Frec. $(\%)$ & Ejemplo representativo \\
\hline $\begin{array}{l}\text { Evento o } \\
\text { contenido } \\
\text { divulgativo } \\
\text { (educación, } \\
\text { conceptos, } \\
\text { etc.) }\end{array}$ & $29(17.9 \%)$ & $\begin{array}{l}\text { Reseña: Uno de los más prestigiosos directores de revistas científicas, el britá- } \\
\text { nico Richard Smith afirma en una entrevista publicada en el diario El Mundo } \\
\text { del } 5 \text { de mayo de } 2007 \text { que: la ciencia consiste en observar fenómenos, desarro- } \\
\text { llar una hipótesis para explicarlos e intentar rebatirla. Pero no haber podido } \\
\text { contradecir esta hipótesis no significa que sea verdadera sino que todavía no } \\
\text { se ha podido demostrar que no lo es. Por eso, cualquiera que lea un artículo } \\
\text { científico debe acercarse al gran escepticismo. }\end{array}$ \\
\hline $\begin{array}{l}\text { Investigación/ } \\
\text { Innovación }\end{array}$ & $64(39.5 \%)$ & $\begin{array}{l}\text { Reseña: En el diario El Mundo, del } 31 \text { de agosto de } 2005 \text {, apareció la noticia } \\
\text { de que un consorcio de } 67 \text { investigadores procedentes de cinco países habían } \\
\text { publicado en la revista Nature el borrador del genoma del chimpancé, que } \\
\text { muestra que el } 96 \% \text { del ADN de este animal es igual al del ser humano. }\end{array}$ \\
\hline $\begin{array}{l}\text { Evento } \\
\text { político- econ. }\end{array}$ & $39(24.1 \%)$ & $\begin{array}{l}\text { En el nombre del desarrollo sostenible. El índice Dow Jones incluye } 17 \text { empre- } \\
\text { sas españolas que destacan por su gestión responsable. }\end{array}$ \\
\hline $\begin{array}{l}\text { Evento } \\
\text { polít.-invest. }\end{array}$ & $12(7.4 \%)$ & $\begin{array}{l}\text { La alternativa de la alternativa. La industria ya estudia sustituir los actuales } \\
\text { biocarburantes por otros de segunda generación. }\end{array}$ \\
\hline $\begin{array}{l}\text { Eventos } \\
\text { negativos } \\
\text { como } \\
\text { desastres } \\
\text { naturales o } \\
\text { tecnológicos, } \\
\text { accidentes o } \\
\text { riesgos }\end{array}$ & $18(11.1 \%)$ & $\begin{array}{l}\text { Reseña: El diario El País del } 25 \text { de abril de } 2007 \text { publicó la noticia de que tres } \\
\text { personas habían denunciado a una multinacional responsable de la fabrica- } \\
\text { ción de un producto de fumigación con productos tóxicos exclusivos para el } \\
\text { campo y que empleó para erradicar una plaga de cucarachas en el casco urba- } \\
\text { no de la ciudad de Hospitalet. El trabajador de la empresa que se encargó de } \\
\text { la fumigación en el verano de } 2002 \text { enfermó poco después de realizar el traba- } \\
\text { jo. Las otras dos personas afectadas por la fumigación son otro trabajador de } \\
\text { la multinacional que acompañó en algunas jornadas al trabajador encargado } \\
\text { de la fumigación y una mujer que en dicho verano iba a comer al mediodía a } \\
\text { un parque cercano a su trabajo, que ingresó en el hospital y le diagnosticaron } \\
\text { sensibilidad química múltiple por haber estado en contacto con plaguicidas. } \\
\text { La Inspección de Trabajo sancionó a la citada empresa por incumplir la ley de } \\
\text { riesgos laborales y el tema se encuentra en los tribunales. }\end{array}$ \\
\hline
\end{tabular}


$\mathrm{Al}$ igual que en apartados anteriores, podemos comparar estos datos con los obtenidos en los trabajos anteriormente citados:

\section{Tabla VI. Comparación de noticias-reseñas por tipo de evento (CMC, local e internacional)}

\begin{tabular}{|l|c|c|c|}
\hline Tipo de evento & $\begin{array}{c}\text { CMC } \\
\text { frecuencia (\%) }\end{array}$ & $\begin{array}{c}\text { Prensa local } \\
\text { almeriense* }\end{array}$ & $\begin{array}{c}\text { Prensa } \\
\text { internac.** }^{* *}\end{array}$ \\
\cline { 1 - 2 } $\begin{array}{l}\text { Evento o contenido divulgat. } \\
\text { (educación, conceptos, etc.) }\end{array}$ & $29(17.9 \%)$ & $11(25,6 \%)$ & $14,2 \%$ \\
\hline Investigación/Innovación & $64(39.5 \%)$ & $14(32,6 \%)$ & $37.5 \%$ \\
\hline Evento político-económico & $39(24.1 \%)$ & $11(25,6 \%)$ & $22.3 \%$ \\
\cline { 1 - 2 } Evento político-investigación & $12(7.4 \%)$ & $7(16,2 \%)$ & \multirow{2}{*}{$20,2 \%$} \\
\cline { 1 - 2 } $\begin{array}{l}\text { Eventos negativos como } \\
\text { desastres naturales o } \\
\text { tecnológicos, accid. o riesgos }\end{array}$ & $18(11.1 \%)$ & 0 & \\
\hline
\end{tabular}

* Datos extraídos de Jiménez-Liso, Hernández-Villalobos y Lapetina (2010).

** Datos extraídos de Dimopoulos y Koulaidis (2002).

Las noticias utilizadas por los libros de texto de CMC siguen una tendencia similar a la presencia de los tipos de eventos en la prensa (local e internacional) de los que tenemos datos. En las tres columnas de la tabla VI se observa que son mayoría el número de noticias que guardan relación directa con las investigaciones-innovaciones que, para el caso concreto de CMC (39,5\%), parece indicar su intención manifiesta de actualización del conocimiento científico con los últimos avances. En segunda posición, en orden decreciente de frecuencias, encontramos los eventos políticos, ya sean económicos o político-investigación, tanto en la prensa como en los libros de CMC (24,1\%), lo que permitiría a los docentes plantear la misma noticia desde diferentes puntos de vista político
(Oliveras y Sanmartí, 2009) para trabajar las controversias sociocientíficas (Pipitone, 2013) o los eventos negativos y catástrofes. Aunque no son mayoritarios $(11,1 \%)$, estos eventos negativos también aparecen en los libros de CMC $(11,1 \%)$, centrados en el calentamiento global (Calentando motores para el deshielo. ABC, 5-6- 2007, McGraw-Hill; El deshielo de icebergs antárticos altera la actividad biológica de su entorno. 22-62007. El país, Edelvives); riesgos para la salud y medioambiente (Alerta científica sobre los riesgos para la salud y el medioambiente de la nanotecnología. ABC, 8-8-2004, McGraw-Hill; El cambio climático agrava el impacto de la sequía actual que ya va para cuatro años. 18-32008, El mundo, Edelvives) o guerras (Rusia deja sin gas a Ucrania y Molda- 
via mientras cae el suministro en Europa del Este. 1-1-2006. El País. Edelvives).

\section{Conclusión}

Los resultados analizados en el presente artículo ponen de manifiesto que sólo cinco editoriales (de 12 analizadas) han tenido en consideración las finalidades de educomunicación presentes en las directrices oficiales (MEC, 2007) para la asignatura de CMC incluyendo noticias de medios de comunicación, con intención manifiesta ${ }^{4}$. El posible motivo que nos planteamos de que los libros con noticias perderían actualidad conforme se aleje del año de edición, carece de valor dado que los bloques temáticos de CMC se prestan ampliamente a utilizar noticias científicas presentes en prensa en todas las épocas y la selección de las noticias no parece seguir criterios próximos a lo noticiable y actual sino en función de la temática curricular (Medio Ambiente y Salud) y la actualización a través de eventos de investigación-innovación más que de eventos negativos o político-económicos que suelen tener mayor presencia, importancia y repercusión en la prensa.

Otro criterio para la selección diferente al curricular hubiera podido ser por proximidad al público destinatario (estudiantes de $1^{\circ}$ de Bachillerato) lo que hubiera obligado a las editoriales a incorporar las redes sociales (twitter, facebook, blogs, etc.) que además son las principales fuentes de divulgación científica (Segado-Boj et. al., 2014).

La escasa importancia que los libros conceden a las noticias también se ha puesto de manifiesto al situarlas mayoritariamente en los anexos, que pueden ser obviados por los docentes y estudiantes preocupados por el exceso de contenidos en el corpus del tema, relegando la educomunicación a aquellos que realmente tienen un interés profundo en desarrollarlo en la asignatura de CMC.

Por todo lo anterior, parece que los libros de texto de la asignatura de CMC están perdiendo la oportunidad de contribuir explícitamente a la educomunicación, explícita en las finalidades de la asignatura, y sin las que los estudiante no podrán desarrollar la competencia científica para participar en los debates públicos que la ciencia suscite, analizar críticamente las controversias sociocientíficas o participar activamente en la toma de decisiones, sumándose a las posibles decepciones de ellos y de sus docentes, descritas al comienzo del presente artículo.

\section{Referencias bibliográficas}

BLANCO-LOPEZ, A.; ESPAÑARAMOS, E. GONZALEZ-GARCÍA, J. Y FRANCO-MARISCAL, A.J. (2015). Key aspects of scientific competence for citizenship: A Delphi study of the expert community in Spain. Journal of Research in Science Teaching, 52(2), 164-198. DOI: 10.1002/tea.21188.

\footnotetext{
${ }^{4}$ En comparación con sus libros de FyQ del mismo nivel educativo.
} 
CHIAPPETA, E.L.; SETHNA, G.H. Y FILLMAN, D.A. (1991). A quantitative analysis of high school chemistry textbooks for scientific literary themes and expository learning aids. Journal of Research in Science Teaching, 28(10), 939-951. DOI: 10.1002/ tea.3660281005.

DÍAZ-MORENO, N. Y JIMÉNEZ-LISO, M.R. (2012). Las controversias sociocientíficas: temáticas e importancia para la educación científica. Revista Eureka sobre Enseñanza y Divulgación de las Ciencias, 9(1), 54-7. DOI: 10498/14624.

DIMOPOULOS, K. Y KOULAIDIS, V. (2002). The socio-epistemic constitutions of science and technology in the Greek press: an analysis of its presentations. Public Understanding of Science, 11(3), 225-241. DOI: 10.1088/0963-6625/11/3/302.

DOMÉNECH, A.M. Y MÁRQUEZ-BARGALLÓ, C. (2014). ¿Cómo justifican los alumnos el desacuerdo científico relacionado con una controversia socio-científica? El caso de la reintroducción del oso en los Pirineos. Revista Eureka sobre Enseñanza y Divulgación de las Ciencias, 11(3), 303-319. DOI: 10498/10498/16585.

FERNÁNDEZ-GONZÁLEZ, M. (2008). Ciencias para el mundo contemporáneo. Algunas reflexiones didácticas. Revista Eureka sobre Enseñanza y Divulgación de las Ciencias, 5(2), 185-199.

GONZÁLVEZ, V.Y CONTRERAS-PULIDO, P. (2014). Empoderar a la ciuda- danía mediática desde la Educomunicación. Comunicar: Revista Científica de Comunicación y Educación, 42, 129-136. DOI: 10.3916/C42-2014-12.

JARMAN, R., Y MCCLUNE, B. (2007). Developing Scientific Literacy: Using News Media in the Classroom. Londres: McGraw-Hill International.

JIMÉNEZ-LISO, M.R.; HERNÁNDEZVILLALOBOS, L. Y LAPETINA, J. (2012). Dificultades y propuestas para utilizar las noticias científicas de la prensa en el aula de ciencia. Revista Eureka sobre Enseñanza y Divulgación de las Ciencias, 7(1), 107-126.

JIMÉNEZ-LISO, M. R., SÁNCHEZGUADIX, M. A. Y DE MANUEL, E. (2002). Química cotidiana para la alfabetización científica. ¿Realidad o utopía? Educación química, 13(4), 60-67. Disponible online en http://www.educacionquimica.info/include/downloadfile. php?pdf=pdf700.pdf\&download=1 [1 agosto de 2016].

JIMÉNEZ-VALLADARES, J.D. Y PERALES, F.J. (2001). Aplicación del análisis secuencial al estudio del texto escrito e ilustraciones de los libros de física y química de la ESO. Enseñanza de las ciencias, 19(1), 3-20.

LAPETINA, J. (2005). La divulgación científica a través de la prensa escrita de Almería (1992-2004). Memoria no publicada para la obtención del DEA. Universidad de Granada.

MEC (2007) Real Decreto 1467/2007 de 2 de noviembre, por el que se estable- 
ce la estructura del bachillerato y se fijan sus enseñanzas mínimas. http:// goo.gl/P8jiIG. [1 agosto de 2016].

OLIVERAS, B. Y SANMARTÍ, N. (2009). La lectura como medio para desarrollar el pensamiento crítico. Educación Química, 20(E), 233-245.

OTERO J. Y CAMPANARIO, J.M. (1990). Comprehension, evaluation and regulation in learning from science texts. Journal of Research in Science Teaching, 27(5), 447-460. DOI: 10.1002/tea.3660270505.

PEDRINACI, E. (2008). ¿Tiene sentido una materia como las Ciencias para el mundo contemporáneo? Enseñanza de las Ciencias de la Tierra, 16(1), 9-16.

PIPITONE, M.C. (2013). Visión del profesorado sobre la implementación de una nueva asignatura: Ciencias para el Mundo Contemporáneo. Tesis doctoral no publicada. Universidad Autónoma de Barcelona.

RIVERA, L. E IZQUIERDO, M. (1997). Presencia de la realidad y la experimentación en los textos escolares de ciencias. Alambique, 11, 117-122.

SEGADO-BOJ, F., CHAPARRO, M.A. Y BERLANGA, I. (2014). La divulgación en los blogs científicos hispa- noparlantes: funciones, fuentes, lenguaje y estrategias retóricas. Revista Prisma Social, 12, 143-172.

SUR, E., ÜNAL, E., \& ISERIES, K. (2014). Primary School Second Grade Teachers' and Students' Opinions on Media Literacy. Creencias sobre alfabetización mediática en profesores y estudiantes de Educación Primaria. Comunicar: Revista Científica de Comunicación y Educación, 42, 119127. DOI: 10.3916/C42-2014-11.

TÁRRAGA, P. Y DE PRO, A. (2013). Cuando hablamos del currículum de CMC, ¿todas las Comunidades Autónomas hablan de lo mismo? Revista Eureka sobre Enseñanza y Divulgación de las Ciencias, 10(1), 11-29. DOI: 10498/14994.

VÍLCHEZ, J.E. (2009). La problemática ambiental en los medios. Propuesta de un protocolo de análisis para su uso como recurso didáctico. Enseñanza de las ciencias, 27(3), 421-432. http://goo.gl/pUHQn8.

WILSON, C. (2012). Alfabetización mediática e informacional: proyecciones didácticas. Comunicar: Revista Científica de Comunicación y Educación, 39, 15-24. DOI: 10.3916/C39-201202-01. 
